\title{
Comparative study of the two more frequent $H F E$ mutations (C282Y and H63D): significant different allelic frequencies between the North and South of Portugal
}

\author{
Carla S Cardoso ${ }^{1,2}$, Pedro Oliveira ${ }^{3}$, Graça Porto ${ }^{1,2,4}$, Christian Oberkanins ${ }^{5}$, \\ Mónica Mascarenhas ${ }^{2}$, Pedro Rodrigues ${ }^{1,2}$, Fritz Kury ${ }^{5}$ and Maria de Sousa ${ }^{*, 1,2}$
}

${ }^{1}$ Molecular Immunology and Pathology, ICBAS, Porto, Portugal; ${ }^{2}$ Molecular Immunology, IBMC, Porto, Portugal;
${ }^{3}$ Department of Production and Systems Engineering, University of Minho, Braga, Portugal; ${ }^{4}$ Clinical Hematology,
Santo António General Hospital, Porto, Portugal; ${ }^{5}$ ViennaLab, Vienna, Austria

An earlier study of reference values of iron parameters in Portugal showed significant differences between populations from northern and southern villages. This study addresses the question of the geographical distribution in Portugal of the two main mutations (C282Y and H63D) of the hereditary hemochromatosis gene, HFE. For that purpose, a stratified sample of 640 anonymous dried blood spot samples was randomly selected from the major regions of Portugal: North, Center, Lisbon and the Tagus Valley, Alentejo and Algarve. Differences in the geographical distribution of these two mutations were observed thus confirming the presumed differences between the age of the two mutations which is compatible with the postulated Celtic/Nordic origin of the $\mathrm{C} 282 \mathrm{Y}$ mutation. The finding of a significantly higher allelic frequency of the C282Y mutation in the North (0.058) than in the South (0.009) could also point to an effect of differential selective forces acting in the different geographical areas of the country. Data on archaeological, ethnographic and linguistic records and on the North/South distribution of Portuguese cattle breeds of European or African origin have also been reported. In addition to their interest for population genetics, the results represent a reminder of the need to take into account regional differences in the design of strategies for population screening of hereditary hemochromatosis. European Journal of Human Genetics (2001) 9, 843848.

Keywords: HFE; hemochromatosis; C282Y; H63D; Iberian peninsula; population genetics

\section{Introduction}

Hereditary hemochromatosis (HHC) is one of the most common hereditary metabolic diseases in Caucasians. It is an autosomic recessive disorder of iron metabolism characterised by increased iron absorption that leads to iron overload of parenchymal cells in several organs. ${ }^{1-3}$ Clinical

*Correspondence: Maria de Sousa, MD, PhD, Molecular Immunology Laboratory, Institute for Molecular and Cell Biology (IBMC), Rua do Campo Alegre, 823, 4150-180 Porto, Portugal. Tel: +351 22 6074956; Fax: +351 22 6098480; E-mail: mdesousa@ibmc.up.pt

Received 9 April 2001; revised 12 July 2001; accepted 19 August 2001 consequences of iron accumulation include cirrhosis of the liver, hepatocellular carcinoma, diabetes, heart failure, arthritis and hypogonadism.

Feder et $a l^{4}$ reported a candidate gene for HHC on chromosome 6 (6p22.1) as a non classical MHC-class I gene denominated HFE, in which two mutations were identified: $\mathrm{C} 282 \mathrm{Y}$ and $\mathrm{H} 63 \mathrm{D}$. The $\mathrm{C} 282 \mathrm{Y}$ mutation predicts substitution of the cysteine residue at codon 282 by a tyrosine in the alpha3 domain of the molecule ${ }^{4}$ and prevents the interaction with beta2-microglobulin and consequently disrupts the HFE structure and function. 5 ,6 The $\mathrm{C} 282 \mathrm{Y}$ mutation in homozygosity is responsible for the majority of HHC cases (for 
review see Porto and De Sousa ${ }^{7}$ ). The H63D mutation results in a substitution in the aminoacid 63 in the alpha1 domain changing a histidine to an aspartate. ${ }^{4}$ The role of the H63D mutation in the pathophysiology of the disease is still unclear.

The frequency of the HFE mutations in control subjects has been reported in several European populations and in populations of European descent. The highest allelic frequencies for the C282Y mutation were found in the Northern European countries, namely in Ireland (an average of $10 \%),{ }^{8,9}$ with a lower frequency (1\%) observed in countries from southern Europe, namely Italy. ${ }^{10}$ The H63D mutation was found in highest frequencies in the Iberian Peninsula (above $20 \%) .{ }^{11,12}$ In non-Caucasian populations HFE mutations were either absent or found in lower frequencies. ${ }^{13,14}$

The present work was motivated by a previous study of reference values of iron parameters in Portugal done before the discovery of the HFE gene. ${ }^{15}$ That study reported regional differences in iron parameters between Northern and Southern villages in Portugal. These differences were observed both in serum ferritin levels in females and in serum iron levels in males from the two regions, with the highest values reported in subjects from the North. These differences were also reflected on the prevalence of iron overload and iron deficiency in the two regions. Iron deficiency was found significantly more frequently in the South, in contrast with iron overload that was found more commonly in the North. $^{15}$

The aim of the present work was to estimate the frequency of the C282Y and H63D HFE mutations in Portugal, comparing its distribution through different regions.

\section{Material and methods}

The National Institute of Statistics (INE) divides Portugal in five major regions: North, Center, Lisbon and the Tagus Valley, Alentejo and Algarve (see Figure 1). Lisbon and the Tagus Valley, being an immigration region from other regions in the country reflects, to a large extent, the whole population in the country.

\section{Sample selection}

In order to compare the prevalence of the C282Y and H63D HFE mutations among those five regions, an anonymous random stratified sample was used. The Portuguese Neonatal Screening Program covers 95\% of all newborns in Portugal. A single laboratory is responsible for the screening at the Medical Genetics Institute. The information of each card is kept in a database and the only accessed information regarding the subjects is the record number and the geographical location, constituting the sampling base.

From this base, a stratified random sample of 640 anonymous dried blood spot samples was selected, through a random number generator, from the five regions of Portugal. The selection of the sample size was based on the previous estimated allele frequency of the $\mathrm{C} 282 \mathrm{Y}$ mutation in a control population from Northern Portugal. ${ }^{12}$ The sample size, taking into consideration the cost and time required for the analysis, was calculated in order to assure a global error below $1 \%$ for a $95 \%$ confidence interval.

The distribution of the 640 genotyped dried blood spot samples according to the five Portuguese regions was as follows: 129 from the North, 130 from the Center, 133 from Lisbon and the Tagus Valley, 132 from the Alentejo and 116 from the Algarve.

\section{DNA purification}

The DNA purification of the dried blood samples was done using the InstaGene ${ }^{\mathrm{TM}}$ Dry Blood Kit (Bio-Rad Laboratories), according to the manufacturer's recommendations. This procedure consists in the selective extraction of amplification reaction inhibitors present in the blood without removing any of the filter-bound DNA. The extracted dry blood spot is added directly to the amplification reaction mixture prior to thermocycling.

\section{HFE genotyping}

The HFE genotyping was done using two commercial kits (Haemochromatosis Gene Mutation Assay I and II, ViennaLab, Vienna, Austria). Briefly, exon 4 (for C282Y) or exon 2 (for H63D) sequences of the HFEgene were amplified in vitro and terminally labelled with fluorescein as a reporter molecule. The amplification products were alkali-denatured, and $25 \mu \mathrm{l}$ aliquots were selectively hybridised to allelespecific (wild type or mutant) oligonucleotide probes immobilised in two separate cavities of a microwell plate. After hybridisation and stringent washes at $37^{\circ} \mathrm{C}$, bound sequences were detected using a horseradish peroxidaselabelled anti-fluorescein antibody and colour reaction with tetramethylbenzidine. The methodology, as well as its validation on samples of known genotype (RFLP-typed) and application for typing were presented elsewhere. ${ }^{16-18}$

\section{Statistical analysis}

The differences among the allelic frequencies in the different regions were tested by contingency table analysis (Chi-square Test). Given that the proportions were close to zero, the confidence limits for the proportions were calculated using a relationship between the $\mathrm{F}$ distribution and the binomial distribution. The multiple comparisons for the proportions were based on a procedure analogous to the Tukey test, based on the angular transformation of each proportion. ${ }^{19}$

\section{Results}

The results obtained in terms of HFE genotypes and the corresponding allelic frequencies of the two mutations by region are summarised in Table 1 and illustrated in Figure 1. The lower and upper 95\% confidence limits for the allelic frequencies in the five regions are also presented in Table 1. 

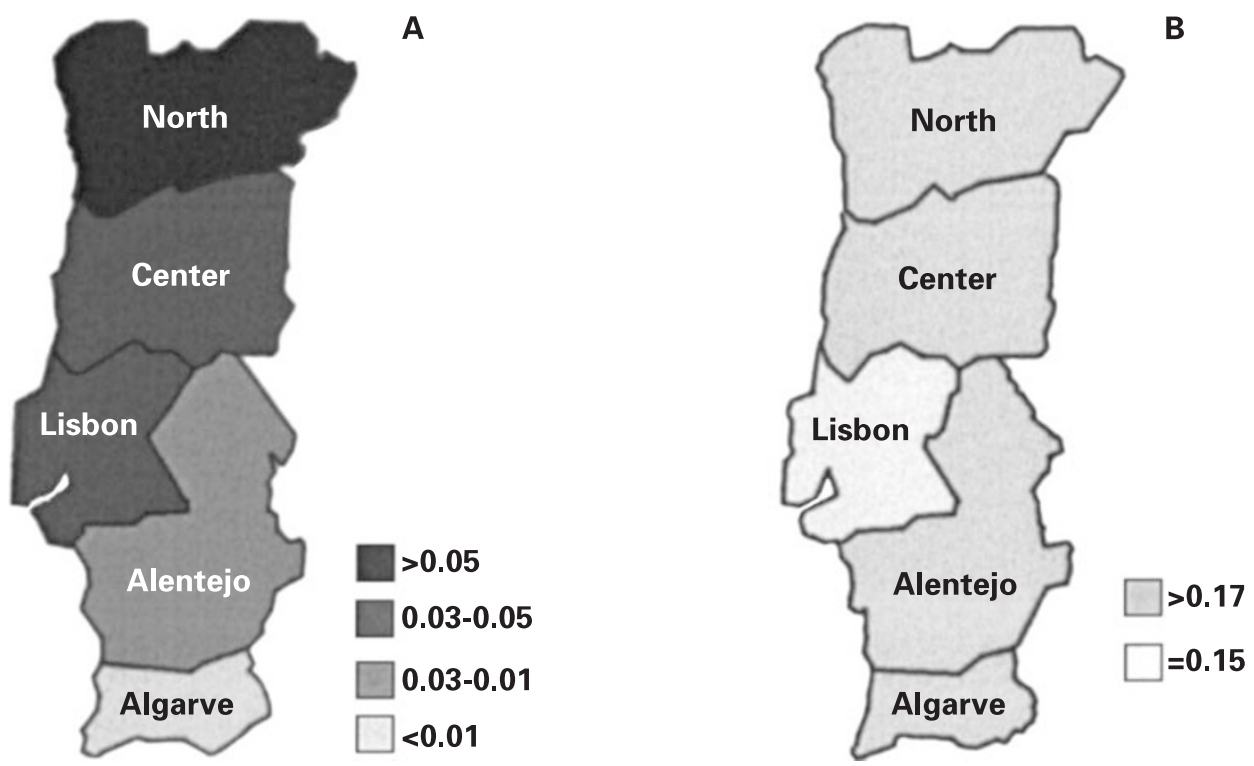

Figure 1 Maps representing the geographical distribution of the allelic frequencies of the C282Y (A) and H63D (B) HFE mutations in the five Portuguese regions.

Table 1 Number of subjects genotyped for the C282Y and H63D HFE mutations, the correspondent allelic frequencies and $95 \%$ confidence limits for the allelic frequencies in the five regions of Portugal. ( $n=$ total number of subjects genotyped)

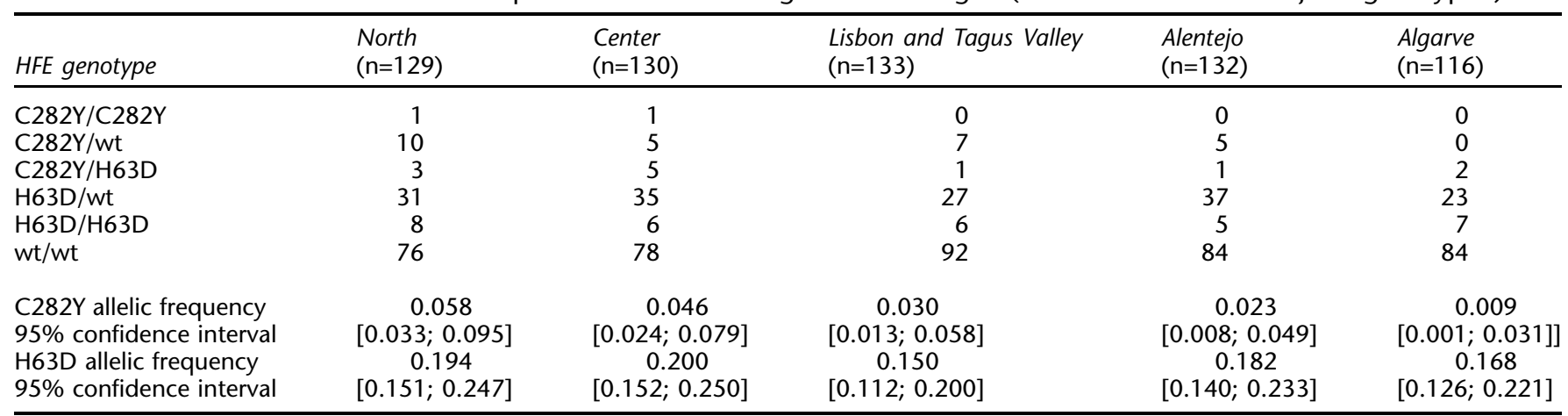

\section{C282Y HFE mutation}

The overall distribution of the $\mathrm{C} 282 \mathrm{Y}$ mutation includes two homozygous and 39 heterozygous samples (12 of the 39 are compound heterozygous for both mutations) (Table 1).

The allelic frequency of the $\mathrm{C} 282 \mathrm{Y}$ mutation decreases from the North to the South. In the North, an allelic frequency of 0.058 ([0.033, 0.095] 95\% CI) was observed contrasting with the allelic frequency of 0.009 ([0.001, 0.031] 95\% CI) observed in the Algarve (Figure 1a, Table 1). The frequency of the C282Y mutation is not independent of the regions tested $\left(\chi^{2}=11.57, P<0.05\right)$. When the frequency of the $\mathrm{C} 282 \mathrm{Y}$ allele was compared between the different regions, applying the Tukey test (Table 2), a significant difference was observed between the North and the Algarve $(q=4.711$, $P<0.05)$ and between the Center and the Algarve $(\mathrm{q}=3.873$,
$P<0.05)$. In spite of a decreasing allele frequency of the C282Y from the North to the South, no other statistically significant differences were seen with the present sample size (Table 2).

\section{H63D HFE mutation}

In terms of global genotype frequencies, 32 homozygous and 165 heterozygous samples (12 of the 165 are compound heterozygous for both mutations) for the H63D mutation were observed. The allelic frequency of the H63D is independent of the region tested $\left(\chi^{2}=2.59, P>0.05\right)$, ranging from 0.19 ([0.151, 0.247] 95\% CI) in the North to 0.17 ([0.126, 0.221] 95\% CI) in the Algarve (Figure 1b, Table 1).

In summary, the regional differences seen in the allelic frequency of the C282Y mutation between the North and the South contrasted remarkably with the homogeneous dis- 
Table 2 Multiple comparisons of the C282Y allelic frequencies between the five different Portuguese regions (Tukey test). The significant differences are highlighted in bold in the table. No other significant differences between regions were found

\begin{tabular}{llllll}
\hline Region 1 & Region 2 & Allelic Diff. & Transf. Diff. & SE & $q$ \\
\hline North & Center & 0.011986 & -1.54692 & 1.77839 & 0.86984 \\
North & Lisbon & 0.028065 & -3.96590 & 1.76839 & 2.24266 \\
North & Alentejo & 0.035413 & -5.28201 & 1.77168 & 2.98136 \\
North & Algarve & $\mathbf{0 . 0 4 9 5 1 9}$ & $-\mathbf{8 . 6 2 5 2 8}$ & $\mathbf{1 . 8 3 0 9 5}$ & $\mathbf{4 . 7 1 0 8 3}$ \\
Center & Lisbon & 0.016079 & -2.41897 & 1.76494 & 1.37057 \\
Center & Alentejo & 0.023427 & -3.73509 & 1.76824 & 2.11233 \\
Centro & Algarve & $\mathbf{0 . 0 3 7 5 3 3}$ & $-\mathbf{7 . 0 7 8 3 6}$ & $\mathbf{1 . 8 2 7 6 2}$ & $\mathbf{3 . 8 7 3 0 0}$ \\
Lisbon & Alentejo & 0.007348 & -1.31612 & 1.75818 & 0.74857 \\
Lisbon & Algarve & 0.021454 & -4.65939 & 1.81789 & 2.56308 \\
Alentejo & Algarve & 0.014106 & -3.34327 & 1.82109 & 1.83586 \\
\hline
\end{tabular}

Allelic Diff: Difference of the allelic frequency in the two regions; Transf. Diff: Transformed difference of the allelic frequency, based on the angular transformation of each proportion, in the two regions; SE: standard error of the difference; q: Tukey statistics q.

tribution of the H63D mutation. Statistically significant differences were observed in the $\mathrm{C} 282 \mathrm{Y}$ allelic frequencies between the global North (comprising the North and the Center regions) and the global South (comprising the Alentejo and the Algarve) $\left(\chi^{2}=3.841, P<0.01\right.$ Fisher's exact test).

\section{Discussion}

The present study demonstrates the existence of significant regional differences in the frequency of the $\mathrm{C} 282 \mathrm{Y}$ mutation and a homogeneous frequency of the H63D mutation in Portugal. The results are in accordance with previously reported differences between biochemical parameters of the iron status in the normal population. ${ }^{15}$ The highest allelic frequency of the C282Y mutation was observed in the North (0.058), approaching allelic frequencies reported in Northern European countries (reviewed in Lucotte, ${ }^{20}$ MerryweatherClarke, ${ }^{21}$ Porto and De Sousa, ${ }^{7}$ Fairbanks ${ }^{22}$ ), in contrast with the frequency in the Algarve (0.009), which is similar to that reported in Italy. ${ }^{10,23}$ The allelic frequency of the H63D mutation observed in this study $(0.15-0.20)$ is among the highest reported in Europe. Similar frequencies were seen in Spain $(0.22)^{11}$ with the highest frequency reported in Basques $(0.30){ }^{13}$

The regional differences in the $\mathrm{C} 282 \mathrm{Y}$ and the constancy of the H63D allelic frequencies raise two questions: (1) The putative age of the two HFE mutations; (2) The possible evolutionary significance of the differences observed in the C282Y allele frequency.

The findings are compatible with the notion of the recent origin of the $\mathrm{C} 282 \mathrm{Y}$ mutation ${ }^{24,25}$ and of an older origin for the H63D mutation as suggested by Risch ${ }^{26}$.

The strategic localisation of Portugal between the Atlantic and the Mediterranean places the country at the convergence of many population settlements, coming from different parts of Europe and Africa. ${ }^{27}$ These settlements, however, did not have the same influence in the whole country. A geographical and cultural boundary could be defined between the north and south, documented by archeological, ethnographical and linguistic records. ${ }^{28}$ This is further supported by more recent studies of the European or African origin of Portuguese cattle breeds. ${ }^{29}$

Simon et $\mathrm{l}^{30}$ postulated that the geographical distribution of hemochromatosis in the world was similar to the migration pattern of Celts, a postulate discussed more recently by Lucotte. ${ }^{20}$ The occupation of the Celts in Portugal occurred in the 6th century $\mathrm{BC}$ and it is believed that the influence of the Celts was predominant in the North. ${ }^{28} \mathrm{~A}$ strong founder effect could thus be an explanation for the marked differences observed. However, it goes against the putative age estimated to be on average 60 generations. ${ }^{24,25}$ Considering that one generation corresponds to about 20 years, the $\mathrm{C} 282 \mathrm{Y}$ mutation should have occurred 1200 years ago, which is more recent than the early Celtic occupation of Portugal. Another possible explanation for the distribution of the C282Y mutation could be the Nordic/Suevian occupation and settlement that occurred between the 5th-6th century only in the North of the country. ${ }^{28}$ A possible later Viking origin has been discussed by others. ${ }^{21,31}$

The frequency of the H63D mutation did not vary between regions supporting an older origin of this mutation. Similarly to the present result, a reported study of 101 Portuguese unrelated males ( 53 from the north and 48 from the south) studied for 18 nuclear polymorphic markers, showed that 16 out of the 18 markers, had no differences in allelic frequencies between North and South suggesting a genetic homogeneity of the country. ${ }^{32}$

Thus, the high $\mathrm{C} 282 \mathrm{Y}$ allelic frequency in the North supports the notion of acting selective forces. ${ }^{25,33-35}$ The C282Y heterozygous subjects could be protected from iron deficiency when dietary iron intake is limited. In the case of the females, they could be protected from blood loss due to menstruation and multiple pregnancies. Interestingly, in the population from the North of Portugal a very high average number of pregnancies ( $>10$ children) was reported in females older than 40 years. ${ }^{36}$ In addition one could speculate that a mutation that favoured iron overload could be negatively selected in areas of high incidence of malaria such as European regions round the Mediterranean. ${ }^{37}$ In Portugal, the highest mortality rate due to malaria was observed in the South. ${ }^{38}$ Similar North/ South discrepancies have been reported in France ${ }^{39}$ and Italy. ${ }^{23,40}$

In conclusion, in addition to their interest for European population genetics, the present and similar results in other countries are a reminder of the need to take into account regional differences in the design of strategies for population screening of hereditary hemochromatosis in Europe and/or in countries with populations of European descent. 


\section{Acknowledgements}

Carla Cardoso is recipient of a PhD fellowship PRAXIS XXI (BD/ 13383/97). We thank Vienna Lab (Austria) for providing the study with kits for genotyping of HFE mutations. We gratefully acknowledge Drs $R$ Vaz Osório, C Sá Miranda and L Vilarinho from the Institute of Medical Genetics (Porto, Portugal) for their interest and support of the present study. We also thank Drs I Vieira, C Vieira and AT Merryweather-Clarke for the helpful discussion of the manuscript. The work was funded in part by a joint grant of the $C$ Gulbenkian and the National Science and Technology Foundations and the financial support of the American Portuguese Biomedical Research Fund (APBRF, USA).

\section{References}

1 Cartwright GE, Edwards CQ, Kravitz $\mathrm{K}$ et al: Hereditary hemochromatosis. Phenotypic expression of the disease. $N$ Engl J Med 1979; 301: 175 - 179 .

2 Cox TM, Lord DK: Hereditary Hemochromatosis. Eur J Haematol 1989; 42: $113-125$

3 Edwards CQ, Griffen LM, Goldgar DE, Drummond C, Skolnick MH, Kushner JP: Prevalence of hemochromatosis among 11,065 presumably healthy blood donors. N Engl J Med 1988; 318: $1355-1362$.

4 Feder J, Gnirke A, Thomas W et al: A novel MHC class I like gene is mutated in patients with hereditary haemochromatosis. Nature Genet 1996; 13: 399-408.

5 Feder JN, Tsuchihashi Z, Irrinki A et al: The hemochromatosis founder mutation in HLA-H disrupts beta2-microglobulin interaction and cell surface expression. J Biol Chem 1997; 272: $14025-14028$

6 Waheed A, Parkkila S, Zhou XY et al: Hereditary hemochromatosis: effects of $\mathrm{C} 282 \mathrm{Y}$ and H63D mutations on association with beta2-microglobulin, intracellular processing, and cell surface expression of the HFE protein in COS-7 cells. Proc Natl Acad Sci USA 1997; 94: 12384-12389.

7 Porto G, De Sousa M: Variation of hemochromatosis prevalence and genotype in national groups; in Barton JC, Edwards CQ (eds): Hemochromatosis: Genetics, pathophysiology, diagnosis and treatment. Cambridge, 2000, pp 51-62.

8 Ryan E, O'Keane C, Crowe J: Hemochromatosis in Ireland and HFE. Blood Cells Mol Dis 1998; 24: 428 - 432.

9 Murphy S, Curran MD, McDougall N, Callender ME, O'Brien CJ, Middleton D: High incidence of the Cys 282 Tyr mutation in the HFE gene in the Irish population-implications for haemochromatosis. Tissue Antigens 1998; 52: $484-488$.

10 Carella M, D'Ambrosio L, Totaro A et al: Mutation analysis of the HLA-H gene in Italian hemochromatosis patients. Am J Hum Genet 1997; 60: 828-832.

11 Sanchez M, Bruguera M, Bosch J, Rodes J, Ballesta F, Oliva R: Prevalence of Cys282Tyr and His63Asp HFE gene mutations in Spanish patients with hereditary hemochromatosis and in controls. J Hepatol 1998; 29: 725 - 728

12 Porto G, Alves H, Rodrigues P et al: Major Histocompatibility complex class I associations in iron overload: evidence for a new link between the HFE H63D mutation, HLA-A29, and nonclassical forms of hemochromatosis. Immunogenetics 1998; 47: $404-410$.

13 Merryweather-Clarke AT, Pointon JJ, Shearman JD, Robson KJH: Global prevalence of putative haemochromatosis mutations. $J$ Med Genet 1997; 34: $275-278$.

14 Cullen LM, Gao X, Easteal S, Jazwinska EC: The hemochromatosis 845 G-A mutations: prevalence in non-Caucasian populations. Am J Hum Genet 1998; 62: 1403 - 1407.
15 Porto G, Vicente C, Fraga J, Martins da Silva B, De Sousa M: Importance to establishing appropriate local reference values for the screening of hemochromatosis: A study of three different control populations and 136 hemochromatosis family members. J Lab Clin Med 1992; 119: 295 - 305.

16 Oberkanins C, Kazemi-Shirazi L, Kury F et al: Genotyping of the hereditary haemochromatosis mutation (HLA-H:C282Y) in microtiter plates. Am J Hum Genet 1997; 61 (Suppl.): A225.

17 Oberkanins C, Kazemi-Shirazi L, Kury F et al: Genotyping of common hereditary haemochromatosis mutations in microtiter plates. Eur J Hum Genet 1998; 6 (Suppl.1): 62.

18 Oberkanins C, Kazemi-Shirazi L, Kury F et al: Genotyping of hereditary haemochromatosis mutations in microtiter plates. $J$ Hepatol 1999; 30 (Suppl.1): 162.

19 Zar JH: Biostatistical Analysis, 4th edn. Prentice Hall, New Jersey, 1999.

20 Lucotte G: Celtic origin of the C282Y mutation of hemochromatosis. Blood Cells Mol Dis 1998; 24: 433 - 438.

21 Merryweather-Clarke AT, Pointon JJ, Jouanolle AM, Rochette J, Robson KJ: Geography of HFE C282Y and H63D mutations. Genet Test 2000; 4: 183-198.

22 Fairbanks VF: Hemochromatosis: population genetics; in Barton JC, Edwards CQ (eds): Hemochromatosis: Genetics, pathophysiology, diagnosis and treatment. Cambridge, 2000, pp 42-50.

23 Restagno G, Gomez AM, Sbaiz L et al: A pilot C282Y hemochromatosis screening in Italian newborns by TaqMan technology. Genet Test 2000; 4: 177-181.

24 Ajioka RS, Jorde LB, Gruen JR et al: Haplotype analysis of hemochromatosis: evaluation of different linkage disequilibrium approaches and evolution of disease chromosomes. Am J Hum Genet 1997; 60: 1439-1447.

25 Thomas W, Fullan A, Loeb DB, McClelland EE, Bacon BR, Wolff RK: A haplotype and linkage disequilibrium analysis of the hereditary hemochromatosis gene region. Hum Genet 1998; 102: $517-525$.

26 Risch N: Haemochromatosis, HFE and genetic complexity. Nat Genet 1997; 17: $375-376$.

27 Horta J: Evidence for a Luso-African identity in "Portuguese accounts a Guinee of Cabo Verde" (sixteenth and seventeenth centuries). History in Africa 2000; 27: 99-130.

28 Ribeiro O, Lautensach H, Daveau S: Geografia de Portugal III. O povo Português: Edições Sá Costa, Lisboa, Portugal, 1989.

29 Cymbron T, Loftus R, Malheiro MI, Bradley DG: Mitochondrial sequence variation suggest an African influence in Portuguese cattle. Proc R Soc Lond B 1999; 266: 597-603.

30 Simon M, Le Mignon L, Fauchet R et al: A study of 609 HLA haplotypes marking for the hemochromatosis gene: (1) Mapping of the gene near the HLA-A locus and characters required to define a heterozygous population and (2) Hypothesis concerning the underlying cause of hemochromatosis-HLA association. Am J Hum Genet 1987; 41: 89-105.

31 Milman N, Graudal N, Nielsen LS, Fenger K: HLA determinants in 70 Danish patients with idiopathic haemochromatosis. Clin Genet 1988; 33: 286-292.

32 Lavinha J, Alves C, Amorim A et al: Genetic diversity of the Portuguese population: the existing geographic and cultural boundary is not reflected in population subdivision. Eur J Hum Genet 2000; 8: 166 (Poster 682).

33 Rochette J, Pointon JJ, Fisher C et al: Multicentric origin of hemochromatosis gene (HFE) mutations. Am J Hum Genet 1999; 64: $1056-1562$.

34 Datz C, Haas T, Rinner H, Sandhofer F, Patsch W, Paulweber B: Heterozygosity for the $\mathrm{C} 282 \mathrm{Y}$ mutation in the hemochromatosis gene is associated with increased serum iron, transferrin saturation, and hemoglobin in young women: a protective role against iron deficiency? Clin Chem 1988; 44: 2429-2432. 
35 Parkkila S, Waheed A, Britton RS et al: Association of the transferrin receptor in human placenta with HFE, the protein defective in hereditary hemochromatosis. Proc Natl Acad Sci USA 1997; 94: $13198-13202$.

36 De Sousa M, Porto G, Fraga J et al: Ann NY Acad Sci 1988; 526: $349-351$

37 Goma J, Renia L, Miltgen F, Mazier D: Iron overload increases hepatic development of Plasmodium yoelii in mice. Parasitology 1996; 112: $165-168$.

38 Filipe AR: O Instituto de Malariologia de Águas de Moura e a luta contra a Malária em Portugal (1996); in Ministério da Saúde Centro de Estudos de Vectores e Doenças infecciosas do Instituto Nacional de Saúde (eds): Trabalhos publicados III (1996-1998). Águas de Moura, Portugal, 1999, pp 41-50.
39 Mercier G, Bathelier C, Lucotte G: Frequency of the C282Y mutation of hemochromatosis in five French populations. Blood Cells Mol Dis 1998; 24: $165-166$.

40 Racchi O, Mangerini R, Rapezzi et al: Mutations of the HFE gene and the risk of hepatocellular carcinoma. Blood Cells Mol Dis 1999; 25: 350-353. 